\title{
O devir-criança, a Polaridade mulher-homem e a Cultura da Paz na formação de educadores/as no contexto da diversidade
}

\begin{abstract}
Resumo
$\mathrm{Na}$ prática pedagógica, enfrentamos o desafio de resistir à padronização consumista das crianças e adolescentes no contexto do Capitalismo Mundial Integrado. Isso pede para assumirmos prioritariamente e com lucidez o devir-criança e o devir-mulher, teorizados por Deleuze e Guattari: o primeiro é referido à figura grega de Dionísio, filosoficamente elaborada por Nietzsche; o segundo, aos problemas levantados pela teoria queer, assim como, à questão das polaridades masculina e feminina, diferentemente pensadas em culturas tradicionais. De maneira mais radical, no contexto brasileiro e numa perspectiva descolonizadora, o autor se refere a pesquisas sociopoéticas detalhadas que mostram o que são o devir-negro(a) e o devir-índio(a) de educadores(as). A chave da sua formação é o devir-vacuidade, portal para a interculturalidade crítica e a transculturalidade.
\end{abstract}

Palavras-chave: Educação Inclusiva. Esquizoanálise. Sociopoética.

\author{
Jacques Henri Maurice Gauthier \\ Ministere de Leducation \\ Nationale - França \\ jacques.jupaty@gmail.com
}

\section{Para citar este artigo:}

GAUTHIER, Jacques. O devir-criança, a Polaridade mulher-homem e a Cultura da Paz na formação de educadores/as no contexto da diversidade. Revista Linhas. Florianópolis, v. 19, n. 39, p. 146-166, jan./abr. 2018. 


\title{
Child-becoming, man-woman Polarity and Peace Culture in the formation of educators in the diversity context
}

\begin{abstract}
In pedagogical practics we deal with the challenge of resisting to consumist padronization of children and teenagers in the context of Integrated Worldwide Capitalism. This asks us to assume primarily and with lucidity the child-becoming and the woman-becoming, theorized by Deleuze and Guattari: the former relates to the greek figure Dionisius, philosophicaly elaborated by Nietzsche; the latter is referred to the problems brought by the queer theory as to the masculin and feminin polarity issue, thought of differently in traditional cultures. On a more radical manner, in the brazilian context and through a decolonizing perspective, the author mentions detailed sociopoetics researches which showcases what are the negro-becoming and the indian-becoming of educators. The key to their formations is the emptiness-becoming, portal to critical crossculturality and transculturality.
\end{abstract}

Keywords: Inclusive Education. Schizoanalysis. Sociopoetics. 
No discurso vigente na minha infância, criar problema era precisamente o que não se devia fazer, pois isso traria problemas para nós. [...] Assim, conclui que problemas são inevitáveis e nossa incumbência é descobrir a melhor maneira de criá-los, a melhor maneira de tê-los. (Judith Butler, 2015, p. 07)

\section{Educar hoje?}

Félix Guattari (1981) desenvolveu o conceito de CMI, Capitalismo Mundial Integrado, numa concepção de luta ambientalista, por coletivos do movimento social auto-organizados, contra a dominação “mundializada” - como se diz na França - e global do capitalismo atual, dominado pelo sistema financeiro e pelo capital especulativo, destruidores da natureza e do ser humano. Essa dominação é global, ou seja, envolve tanto o lado psicológico, como político ou econômico. Conforme Nietzsche apontou', existem sempre narcóticos que tornam suportáveis e até, desejáveis, essas alienação e renúncia à ativação das suas próprias potências. Segundo Michael Hardt e Antonio Negri (HARDT; NEGRI, 2014), estamos presas/os por quatro fantasmas invasores, potentes drogas íntimas: a mídia, que modela e aprisiona nosso pensamento; a segurança, frente à precariedade crescente do trabalho e ao desemprego; a democracia representativa, na qual renunciamos à nossa liberdade e ao nosso vir-a-ser, dando nossa vida a representantes - em lugar de energizar, por esforço próprio, autogerido, a realidade social; enfim, o consumismo como competição dos desejos e dos narcisismos pelos bens criados pelo mercado, com seu motor, o sistema do crédito, que coloca cadeias nas nossas pernas - cadeias paradoxais pois, em lugar de nos imobilizarem, nos fazem correr e nos agitam, fora de nós, nos limiares da vida (comportamentos borderline), em busca do cumprimento das nossas obrigações de "seres bons", ou seja, consumidores com selo de autenticação.

Não há dúvida de que nossos filhas e filhos, tais como são criadas/os hoje em casa, na escola e na rua, estão se tornando excelentes cidadãos deste mundo, terceirizando suas potências de vida desde antes de nascerem. Obviamente, os dados não estão

\footnotetext{
${ }^{1} \mathrm{O}$ dossiê da dor e dos narcóticos inventados pela Moral para dar um sentido à dor é excelentemente tratado em Giacoia Júnior: Nietzsche - O humano como memória e como promessa (2013).
} 
definitivamente jogados. Pois, como escreveu Nietzsche, quem joga dados e configura nosso mundo tal como é ou tal como pode ser é uma criança, a criança-Dionísio, ou seja: a reatividade, coroada no nada de vontade após a vontade de nada, coroamento do qual nos aproximamos neste início de terceiro milênio - já que nos deixamos carregar pelo ritmo mórbido das promoções dos centros comerciais, dos domingos de eleição e das cobranças dos cartões de crédito (sem falar dos esportes altamente globalizados e dos fins de semana de cerveja e churrasco) - não é um destino insuperável. Nós educadoras e educadores, podemos, cada um/a com sua força e fé, sem necessariamente nos tornarmos heróis da pedagogia, mudar o curso dessa vida mortífera. Como? Ao desenvolvermos, dentro de nós, um devir-criança, aquele devir dionisíaco que permita ressoar nas crianças e despertar, nelas como dentro de nós, a criatividade genuína do desejo, da potência de vida, de fazer encontros e ligações potencializadores, pelos quais nos educamos - nos colocamos para fora, conforme a etimologia - na grande aventura da descoberta do mundo e da cocriação do nosso próprio mundo, em interação com outros (quanto mais heterogêneos, melhor!).

\section{O devir-criança, entre Nietzsche e Deleuze-Guattari}

A noção de "devir-criança” é particularmente elaborada em Mil Platôs, 10 - 1730: Devir-intenso, devir-animal, devir-imperceptível, nas entradas “Plicatura” e "Lembranças de um espinozista II" (DELEUZE; GUATTARI, 1997, p. 41-47). As crianças sabem compor seus afetos, conectar-se com elementos da natureza de maneira criativa, sem hierarquia nem transcendência, pequenos anarquistas experimentadores das suas potências de vida que geralmente a educação engessa em verticalidades castradoras, "disciplinadoras" ou “sedutoras" (conforme o primeiro e o último Foucault, 1975 e 1984). Pensar é compor afetos: as crianças são mestras no pensamento: "Não se trata de animismo, não mais do que de mecanismo, mas de um maquinismo universal: um plano de consistência ocupado por uma imensa máquina abstrata com agenciamentos infinitos" (DELEUZE; GUATTARI 1997, p. 42). Ao retomar criticamente o famoso caso do "Pequeno Hans", estudado e “edipianamente" ${ }^{2}$ interpretado por Freud (2014) nas Cinco psicanálises, Deleuze e Guattari

\footnotetext{
${ }^{2}$ Permito-me esse jogo de palavra, já que para Deleuze e Guattari, a edipianização do ser humano e, particularmente, da criança, era... uma piada!
} 
(1997, p. 44). mostram o quanto a criança é espinozista, espontaneamente, ao pensar por “composição de velocidades e de afetos entre indivíduos inteiramente diferentes, por simbiose [...]", muito distante dos fantasmas freudianos de castração familiar A criança não está visceralmente ligada a papai-mamãe, e sim percorrida de devires-animais. 0 animal, aí, “nem representa os pais” [Freud], “nem a pulsão” [Jung], ele é “a pulsão em pessoa, e não representa nada" (p. 45). A criança é uma mestra no pensamento, pois, ela cria agenciamentos para resolver seus problemas, cujas saídas foram barradas pelo mundo instituído. Não se trata de fantasma, e sim de pensamento; de criação de um plano para pensar.

No nosso devir-criança, aprendemos a brincar, aprendemos a pensar; a desmanchar o mundo ilusório dos fetiches mercantis, dos valores reativos instituídos que criam em nós um corpo de consumidor-consumido. Nosso devir-criança como educadoras e educadores é necessário, indispensável para ecoar, ressoar na própria criança, apoiando-a na sua resistência à captura do seu corpo-mente-espírito pelos poderes do CMI.

Através da criança Dionísio, Nietzsche elaborou o dossiê da criança pensadora, da criança filósofa. "O herói é alegre, eis o que escapou até agora aos autores de tragédia”, exclama Nietzsche no Nascimento da tragédia (2007). A criança é pura afirmação, é um sim à vida que está se fazendo nela, por composições, encontros casuais em que tudo ainda é possível, além do bem e do mal, em que cada vez é a primeira vez, num jogo infinito de transmutações. Por natureza, a criança é instituinte. Não a criança real, empírica, mas a criança do devir-criança - e no mundo de hoje, infelizmente, seria bom que muitas crianças vivenciassem um devir-criança - que lhes foi barrado como pequenas consumidoras, devoradoras de si (e dos outros!), tendo entregue suas forças vitais e criativas ao mundo dos celulares e jogos eletrônicos antes mesmo de nascerem, prelúdio grotesco às buscas da certidão de serem amadas no Facebook quando adolescentes...

Dionísio, na cultura grega, é um paradoxo... Desmembrado e comido - primeiro, cozido e, em seguida, assado - pelos Titãs (imagem terrível da espécie humana comedora de carne, conforme Detienne, 2009, p. 83), aberto a devires múltiplos (assim como, hoje em dia, aponta a teoria Queer), expressando de maneira direta e não linear os deviresanimais da pulsão (o que é a criatividade cultural e individuação mesmo), ele é também, 
segundo os Órficos vegetarianos da Grécia antiga, o príncipe da unidade conquistada entre animalidade, humanidade e divindade, o grande transmutador do qual NietzscheZaratustra precisava, o estrangeiro, o forasteiro oriental numa cultura grega demais certa, onde reina a partilha entre bestas (e mulheres, no limiar desse reino sombrio), de um lado, homens-cidadãos-machos-livres de outro, e por fim, deuses imortais (ver Detienne, 1998, p. 150).

Dionísio, ao se vingar das mulheres submissas que recusam lhe pagar seu tributo, chamando-as pelas florestas onde enlouquecem, comendo carne crua e até, sua própria prole, contesta radicalmente a ordem instituída, a partilha bem ordenada entre animais, homens e deuses, entre homens e mulheres, no polo oposto dos Órficos, já que a recusa do sacrifício sangrento de animais aos deuses, delimitando assim as partes divinas, humanas e animais, passa pela volta a condutas de feras, polo oposto ao vegetarianismo. Os filósofos cínicos (os “cães”) continuarão, no plano do pensamento, a contestação radical da ordem da polis, da cidade, até Diógenes cuspindo sua própria língua na cara do tirano.

O que está em jogo no Dionisismo que Nietzsche obviamente não podia ver, ao considerarmos o machismo da sua época, é, conforme Marcel Detienne (1998, p. 203), a radical contestação realizada da partilha de status entre gêneros na sociedade grega: "Entre a mulher e o homem, entre a bestialidade impura da primeira e a pura espiritualidade prometida ao segundo [...], o Orfismo exila as selvagens violências de Dionísio no mundo animal da mulher"... A posição polêmica e instituinte de Dionísio, inclusive, como criança, pede para assumirmos, como educadoras e educadores, nosso devir-mulher, cujo desejo não pode ser capturado pelo aparelho de estado patriarcalmachista. Não estamos destinadas à reprodução e casamento, e sim, a corridas com lobos em florestas, a metamorfoses repentinas na prática educacional, nem como mães nem com tias, conforme a advertência de Paulo Freire, 2013, e sim como agenciadoras ou catalisadoras de desejos inesperados em sala de aula, vista como mundo selvagem da floresta de antes da alta civilização do CMI instituído.

Portanto, acredito que o caminho real rumo ao devir-criança é o devir-mulher do educador, seja ele, macho ou fêmea. No sentido dionisíaco da palavra, longe de qualquer figura de esposa e mãe, tia e fada. O educador, a educadora, tem papel de despertar e 
fortalecer a bruxa nele, nela, para, através de dispositivos vibracionais, despertar na criança a criatividade genuína que, para além do bem e do mal, tem campo aberto para experimentar as mais inesperadas ligações, alianças e misturas, eróticas por definição (pulsionais, expressando a vida na sua força genuína). Não somos boas nem bons, as crianças não são anjinhos, somos experimentadores/as da vida, conforme já entendeu e teorizou Célestin Freinet (1998). Nós: educadoras, educadores, “educandos" e educandas" (como se diz, na psicanálise, “analisando", "analisanda”).

\section{Nossas polaridades e entre as polaridades}

O devir-mulher, pelo qual passam todos os educadores de qualquer gênero, desde que queiram se libertar do machismo ambiente, é diferente da Anima, segundo Jung (1995), sombra inconsciente do homem (macho), particularmente identificável através das imagens míticas da fada e da bruxa, da jovem virgem e da Grande Mãe devoradora de qualquer forma de diferenciação, discernimento e lucidez.

Em Deleuze e Guattari, esse devir segue a forma da garota tal como se encontra na obra romanesca de Marcel Proust. Trata-se para nós, de maneira menos literária, de pegar pelo devir-mulher a linha dominada de um veneno dualístico, para acabar com qualquer forma de dualismo. Começar e/ou fortalecer em sala de aula um processo de libertação em relação aos dualismos que nos devoram (homem-mulher, branco-negro, adultocriança, humano-animal) - para que se possam tecer novos arranjos, novos dispositivos transgêneros, transraciais, transgeracionais e transespécies - é, de fato, assumir a linha dominada nas relações de gênero, pois todas e todos sentimos o aspecto crucial das relações de gênero em nossa cultura, desde a cozinha até a cama.

A cereja no bolo é que o devir-mulher pode facilitar o despertar da criança para quem tem dificuldade em se relacionar diretamente com sua criança interior - por ter aprendido muito cedo a seriedade, pensada por Nietzsche como traço específico do ideal ascético.

São múltiplas as culturas que valorizam o equilíbrio entre as polaridades masculina e feminina em nós, do xamã mongol que se veste de mulher para possibilitar sua viagem entre os mundos (ver a contribuição decisiva sobre o xamanismo feminino de Tedlock, 
2008) ao iogue que equilibra suas energias para alcançar o estado de consciência desperta. A depender das culturas, não fica muito claro o que é chamado de feminino e masculino, mas podemos nos convencer da urgência de parar de engavetar os meninos em tarefas de "meninos" e as meninas em tarefas de "meninas" - tais como nossa sociedade patriarcal e machista os define. Na prática pedagógica, podemos cuidar em não reforçar esses estereótipos e, pelo contrário, nos “polarizar” e polarizar nossas intervenções de maneira equilibrada, independentemente de qualquer gênero de educadoras/es ou alunas/os.

Considerando a obra de Judith Butler (2015), a teoria Queer traz, como diria Nietzsche, outras perspectivas - que superam a noção de "polarização" - permitindo sair da ilusão platônica das essências eternas. Obviamente, nós educadoras/es temos de desconstruir a essencialização dos gêneros que o patriarcado imprimiu em nós, desde a infância e até, antes de nascermos (pelo discurso e pelas simbolizações sociais, as expectativas dos pais etc.). Numa visão pragmatista, as palavras são atos, palavras de ordem, palavras que mandam e "fazem" o que acreditamos ser. A instituição (no sentido da Análise Institucional, conforme Lourau, 1993 e 2014) da sexualidade e das relações de gênero cria relações de poder e dependência, saberes internalizados do possível e do impossível (do que pretende ser real e racional, "normal”), por meio de palavras, gestos, hábitos, subentendidos, olhares etc. presentes e insistentes na vida cotidiana. É interessante a possibilidade subversiva dada a nós, educadoras e educadores, e principalmente, aos nossos alunos e alunas, de ter uma relação crítica com os papéis sociais pré-definidos, de se criar como pessoa fora dos padrões instituídos, de forjar seus corpos, suas relações com a noção de gênero, ao transitarem naquilo que ainda não tem existência consolidada. A poética da criança é a experimentação mesma das diferenças, e consideramos possível uma escola que respeite esse gênio experimentador das crianças, na continuação de Freinet e tantas outras e outros pedagogos e pedagogas. Por essa razão, há que se oferecer um ambiente educacional rico, complexo e variado (livros, filmes, computadores, jogos...), que solicite as crianças, individual e, sobretudo, coletivamente, no sentido de explorarem um mundo aberto àquilo que, no mundo familiar, social e da mídia ordinária, é desconhecido ou, até, rejeitado. 


\section{Um devir-negro, um devir-negra}

Impressionante é a desvalorização dos traços físicos e culturais da população negra e mestiça do Brasil, assim como, a internalização dessa desvalorização, ainda hoje, no seio de famílias afrodescendentes. Se a sociedade é doente de sexismo, ela é, também, doente de racismo. É impossível pretender ensinar numa ética da igualdade na diferença, da justiça e do combate ao preconceito sem desconstruir, em sala de aula, os padrões culturais racistas.

Aqui, entramos no paradigma estético-político das Três ecologias (do meio ambiente, das relações sociais e da subjetividade humana) segundo Guattari (1990), pois, frente à desvalorização da sensibilidade, do corpo e do sagrado pela ciência positiva cuja aprendizagem é o núcleo dos currículos na Educação instituída -, as tradições culturais dos povos que os Europeus colonizaram, indígenas e africanos notadamente, conferem a maior importância às aprendizagens vivenciadas na comunidade, através do corpo, do jogo, da dança e de iniciações ao sagrado. Isso não significa que as abstrações e a conceitualização inexistem. Mas essas abstrações sempre ficam em contexto, relacionadas ao "aqui e agora" no qual mostram sua força e produzem efeitos. É um modelo potente para aproximar as matérias curriculares, cujo sentido suscetível de provocar o interesse dos alunos e alunas, frequentemente não aparece em sala de aula. Ensinar de maneira abstrata o respeito aos corpos, mentes e espíritos negros é necessário, mas não suficiente. Obviamente, o conhecimento do aporte das culturas indígenas e africanas ao mundo de hoje (e não apenas, à história do Brasil) desenvolve um papel importante na desconstrução do racismo. Mas vivenciar práticas de ensinoaprendizagem afrodescendentes - ou indígenas - traz dimensões que não estão ao alcance da mera compreensão racional.

Trabalhar com a diversidade e heterogeneidade cultural em sala de aula com pertinência implica não apenas ter informações sobre as culturas não eurodescendentes, mas também, ser capaz de instituir práticas pedagógicas e didáticas não eurodescendentes. As pedagogas e pedagogos podem e devem, com razão, pedir formações em maneiras não eurodescendentes de transmitir conhecimentos. Provavelmente, tudo não pode ser transferido do ambiente cultural originário para a sala de aula (mesmo se pensamos essa "sala de aula" como deslocada num espaço aberto), 
mas é fácil imaginar o quanto podemos nos aproveitar pedagogicamente das tradições de escuta e fala coletiva, de colaboração nas tarefas e pesquisas - extremamente relevantes no mundo de hoje dominado pelo individualismo e pela tendência a considerar o outro como uma mera ferramenta para a satisfação de desejos egocentrados.

\section{Desconstruindo e rizomatizando a partir de identidades molares}

Em Deleuze e Guattari, o molar se opõe ao molecular. O molecular é suficientemente flexível e maleável para fazer rizoma e entrar em múltiplas composições heterogêneas e diferenciadas: uma molécula de água no ponto de ferver pode encontrar uma molécula de folha de chá e nós, tomarmos nosso café da manhã. O molar já alcançou o estado de forma, pode-se dizer que ele tem uma essência fixa: "A" água. Na moral, segundo Spinoza ou Nietzsche, acontece o mesmo: um afeto é molecular, ele pode se compor com outros afetos e nós, experienciarmos tristeza ou alegria, estados doentes ou saudáveis. Ao contrário, desde que rigidificamos e essencializamos o Bem em si como forma pura - na herança de Platão - estamos condenadas/os a ser escravas/os de valores transcendentes, ditados pelas forças de dominação social.

Numa pesquisa já antiga, desenvolvida na Faculdade de Educação da Universidade Federal de Santa Catarina (ver Gauthier, Fleuri, Grando, 2001), seguimos o caminho nietzscheano de desconstrução do platonismo, ao formar um grupo-pesquisador sociopoético procurando no seu próprio seio o imaginário do "Índio", do "Negro", do "Branco" - imagens molares ideologicamente formadas e apropriadas (de maneira, por certo, diferente) por cada um dos membros do grupo-pesquisador, copesquisadoras e copesquisadores.

Para apresentar a sociopoética, retomarei as "Cinco Estrelas" que a orientam - tais como são definidas num artigo escrito para o Primeiro Congresso sobre Gênero, Educação e Afrodescendência, organizado pela Universidade Federal do Piauí (2013), sendo a primeira estrela a noção de grupo-pesquisador, responsável e autor da pesquisa, a partir de um tema-gerador, negociado entre ele e o/a facilitador/a da pesquisa (ficando secreta a pergunta precisa a ser colocada ao grupo em estado de total relaxamento, para que se torne possível o surgimento de imagens não conscientes nem socialmente induzidas). 
1) Influenciada pela Análise Institucional, pelos Grupos Operativos e pelos Círculos de Cultura, a noção de grupo-pesquisador era gerada num ambiente de racionalismo crítico, de cuidado político para com a exigência de desvelar e criticar toda e qualquer opressão possível e para com a urgência de energizar e catalisar a criatividade grupal e individual, sem que as diferenças estejam apagadas em nome do consenso ou da abstração de uma norma, e sim potencializadas como manifestações impares da diversidade encantadora da vida (ver Gauthier, 2012). Para que penetremos no ethos afrodescendente, em lugar de ficarmos enraizadas/os no ethos eurodescendente racionalista-crítico, faltava apenas a ampliação do nosso cuidado com a autogestão libertária e libertadora (das potências de agir, das liberdades e alegrias de todos e de cada um/a) para quatro reinos que não contemplávamos: o reino mineral, o reino vegetal, o reino dos ancestrais e o reino dos "ventos sagrados", daqueles seres de luz que são os orixás. Por essa razão proponho hoje uma leve modificação do nosso ângulo de visão, ao completarmos - sem abolirmos o trabalho eurodescendente crítico e criativo já finalizado - a noção de "grupo-pesquisador" pela sua integração no mundo dos vivos e dos mortos, das pedras e dos deuses, dos vegetais e animais. Caberá entendermos os efeitos cognitivos e práticos de tal ampliação. Já está chegando uma leve inquietação: como pedras e orixás vão participar da elaboração de problemas, criação de confetos $^{3}$, atribuição de personagens conceituais no processo de pesquisa? Dá um leve nó na garganta.

2) A partir de práticas de lutas anticolonialistas e antineocolonialistas foi apontada a necessidade de que se leiam os dados de pesquisa do ponto de vista de múltiplos olhares, valorizando acima de tudo os das populações oprimidas, marginalizadas, silenciadas ou invisibilizadas. Tratava-se de descolonizar os espíritos das/os cientistas acadêmicas/os, ao evidenciar outras formas de racionalidades que, contrariamente ao racionalismo eurodescendente, aceitam e precisam da intuição, do mistério, do sentir e do vivenciar para serem eficientes. Ao passar do tempo, tornou-se evidente que podíamos também criar dados através de dispositivos tais como rituais indígenas ou afrodescendentes, o que já era bem ousado. A academia não estava acostumada a ver encantados ou orixás fornecerem informações às/os facilitadoras/es de pesquisa, ainda menos dar dicas para a interpretação dos mesmos. Hoje chegou o tempo de teorizar essa possibilidade, o que

\footnotetext{
${ }^{3}$ Um confeto é uma mistura de conceito e afeto, com o qual pensam os seres humanos.
} 
permitirá, ao mesmo tempo, criar um entrelugar entre o mundo encantado dos espíritos da mata e o mundo da academia pós-weberiana - ou seja, desencantada - e seduzir as/os acadêmicas/os com quem convivemos para que participem, sem medo no coração, das avaliações dos nossos trabalhos.

3) Na continuidade lógica dessa valorização das culturas que chamávamos de “populares" e "de resistência", proclamávamos nossa verdade: o corpo na sua integralidade, com todas suas potências, sensíveis, racionais, intuitivas, emocionais, gestuais, imaginativas etc. participava da pesquisa, do cuidar e da educação, e não apenas o cérebro esquerdo, sede da razão analítica comumente mobilizada nas pesquisas acadêmicas - frequentemente limitadas a questionários e entrevistas. Agora nossa tarefa é de encontrarmos a nós mesmos como corpos negros, pelo menos durante a ativação do dispositivo de pesquisa. Vale à pena estudar esse corpo negro que queremos para nós (independentemente da nossa cor atual de pele) e os seus modos de agir, falar, pensar.

4) Misturar arte e ciência, ao violarmos um tabu do modelo dominante de criação dos conhecimentos científicos, foi a via real que encontramos para fazer ciência de um jeito satisfatório, ou seja, que favoreça a mobilização - muito desejada - de todas as potências de conhecer do corpo. Estávamos no mundo neo-freudiano e neo-marxiano da busca do inconsciente, das verdades recalcadas, daquilo que podia ser implícito por ser demais óbvio no mundo cultural da/o produtor/a de dados, ou diferentemente, recalcado por ser perigoso, traumático, ou ainda, escondido pela ideologia dominante e coisas assim. Hoje chegou a hora de ampliar a nossa compreensão daquelas brincadeiras chamadas de "técnicas de produção de dados", ao enegrecê-las no sentido da sua sedução pelo jogo ritualístico cósmico do qual participam os corpos negros na capoeira, na dança dos orixás e no afoxé ou, de maneira mais radical, no transe e na iniciação. Uma promessa posso fazer: que saiamos daqui mais puros que entramos. Será que vou cumprir essa promessa?

5) Enfim, a última negrestrela criada para ser mais que contemplada é a da responsabilidade, em todos os cantos, do grupo-pesquisador, ética, cognitiva, espiritual, política e social, no decorrer e na finalização da pesquisa. A comunidade anfitriã da pesquisa tem o direito fundamental de querer efeitos para ela; e mais, de negociar os efeitos da pesquisa em geral no universo social. Será que existem também negociações e 
efeitos espirituais? Uma sociopoética negra pede para que cuidemos de explicitar esses efeitos e negociações, o que pode dar a você como a mim uma leve sensação de vertigem.

Temos aqui as ferramentas para desenvolvermos pesquisas sociopoéticas com tema-gerador o devir-negro ou o devir-índio. Falaremos mais tarde de uma pesquisa introdutória ao devir-índio, um pouco como a pesquisa sobre o imaginário do "Índio", do “Negro" e do "Branco" pode ser considerada introdutória a pesquisas sobre os devires.

Ao reler o livro publicado como produto e avaliação (no sentido de Freinet, para apreciação de um público exterior à escola) da referida pesquisa, realizada com sete alunas e alunos do Programa de Pós-Graduação em Educação da UFSC e o Prof. Dr. Reinaldo Fleuri, destacam-se as seguintes conclusões, principalmente oriundas da técnica do Teatro-Imagem, conforme Boal (1988), adaptada ao dispositivo de pesquisa:

- Sendo o grupo-pesquisador formado de brancas e brancos (culturalmente brancas/os, considerando que podem também ter sangue "misturado", como muitas/os brasileiras/os), ele elaborou uma percepção das/os indígenas como vivenciando um conflito entre a conservação do passado em harmonia com a natureza, os ataques colonizadores dos quais são vítimas e a vontade de irem ao encontro do mundo branco. Vistas como eminentemente espirituais, as tradições indígenas são colocadas na posição de um olhar que nos vê e que não vemos - das quais esperamos uma sabedoria e espiritualidade perdidas. Escrevemos (GAUTHIER, FLEURI, GRANDO, 2001, p. 67): “Este olhar é o 'olhar de fora', aquele olhar que vê o que os outros não podem ver; ele é o 'nonsense', o olhar paradoxal, o ponto cego da formação cultural brasileira". E, na continuação:

Ele parece ter o papel daquela força mística que poderia, em interação com a natureza e, mais globalmente, com o elemento feminino em nós, reforçado pela nossa busca de integração (com os outros e nós mesmos como pessoas), se contrapor à violência colonizadora das igrejas.

Para resumir, para o grupo-pesquisador, o “Índio" é um tradutor da morte em vida, da marginalização em força espiritual conquistadora. 
- A percepção do "Negro" enfatizou o papel da mulher negra dando sua energia para incentivar o homem a sair, assim como, o vai e vem entre a privacidade e a vida comunitária. Esse aspecto ecoou com uma cultura de lutas considerada núcleo para "a união dos marginalizados de todas as culturas" (GAUTHIER, FLEURI, GRANDO, 2001, p. 62-63). O mundo negro seria como o "outro", o positivo do mundo capitalista negador da humanidade: opressor, individualista e consumista. $\mathrm{O}$ olhar do "Negro" é construído pelo grupo-pesquisador como olhar de ternura e beleza, epistemologicamente superior ao olhar acadêmico, por ser intimamente integrado à comunidade e à natureza, enquanto a tendência da academia é de viver de cortes, separações e engavetamentos.

- Os "Brancos" do grupo-pesquisador olhando as imagens que eles têm do "Branco" destacam a sua soberba impondo uma verdade única, e, sobretudo, seu não saber, a partir dessa verdade, sobre "aonde ir", nem "como" (ir aonde ele não sabe). Disciplinando os corpos outros e seu próprio corpo, o "Branco" aparece como frágil, precisando de orientações do Além para conseguir trilhar seu caminho. Assim acontece uma forma de paralisação, pela falta de interação com as outras culturas, acentuada quando o dinheiro se tornou o principal jeito de se comunicar.

Interessante esta forma de inversão da realidade de dominação racial: na nossa pesquisa, o "Branco" aparece como não-índio e não-negro; ele é definido pelo que ele não é. Suas características são na maioria das vezes negativas, enquanto os povos vítimas da colonização trazem virtudes positivas, tanto individual e coletivamente, como no plano epistemológico (um detalhe instigante: apareceram as qualidades positivas da mulher negra e da mulher indígena, enquanto não apareceu nenhuma "mulher branca"). Com efeito, no que diz respeito à construção do saber, foi muito valorizado o que podemos chamar de "saber-fazer coletivamente" das civilizações não eurodescendentes.

Para nós, educadoras e educadores, interagir com as culturas dominadas e o movimento social em geral nos dá as chaves para aprendermos a co-construção coletiva do conhecimento, que não é uma tradição escolar nem universitária. 


\section{Um devir-adolescente, de adultos... e adolescentes}

Nunca encontramos essa expressão: devir-adolescente, em Deleuze e Guattari. No entanto, a pesquisa realizada no Projeto Servir (atividade de extensão do CEFET - Rio de Janeiro) de formação técnica em três anos, em parceria com as comunidades, de adolescentes faveladas/os - afrodescendentes, na maioria - chama para tal devir. Essa pesquisa foi a pesquisa matriz da sociopoética, revisitada uns 20 anos depois no Oco do vento (GAUTHIER, 2012),

- No mundo real, as/os adolescentes, ao mesmo tempo têm dificuldade em imaginar uma existência sem ajuda e assistência, e "estão muito perto de uma crítica lúcida do assistencialismo" (GAUTHIER, 2012, p. 159). Com efeito, expressam com bastante clareza que as educadoras e educadores projetam suas falhas nelas e neles, tentando tratar seu sentimento de culpa - por se considerarem privilegiadas/os da classe média - ao darem apoio a meninas e meninos chamadas/os de "carentes". Mas esses adolescentes recusam totalmente a ideia de que seriam "carentes". O devir-adolescente passa pela crítica da culpa enraizada nas educadoras e educadores! O nosso deviradolescente significa ver as nossas falhas, ao deslocarmos nossa perspectiva de vida, numa visão de mais gratidão e satisfação pelo que nos é dado.

- Esse devir, na sociopsicologia cognitiva, é visto pelos jovens como interdependência entre o grupo que tem acesso privilegiado à formação acadêmica e os jovens excluídos. Agora, sem a relação das/os privilegiadas/os com as/os excluídas/os, as/os primeiras/os não encontram felicidade alguma, e criam pouco saber e pouca sabedoria. Do seu lado, a condição da felicidade das/os excluídas/os é a aceitação da realidade opressiva, sem esperança de mudá-la e até, com muita resignação (diferentemente dos adultos), mas encontrando felicidade e amor nas relações tecidas no seu próprio grupo social e geracional.

- A interação dos devires-adolescentes no grupo adulto e no grupo adolescente proporcionou um vazio, uma vacuidade, um silêncio interior desestabilizador das certezas e categorizações instituídas. Olhares recíprocos, espelhos mostrando imagens inesperadas e heterogêneas caotizaram os seres, abrindo tempos e espaços para se criarem de outro jeito, com mais complexidade, vitalidade, compaixão para consigo, 
assim como para a/o outra/o, mas sem culpa, e sim alegria: uma Cultura da Paz estava caminhando na pesquisa.

O paradigma estético-político segundo Guattari (1992) revelou sua pertinência, já que as atividades teatrais, literárias (de "história a continuar, a partir de uma situação paradoxal ou conflituosa") e plásticas foram fecundas mediações para a construção coletiva do conhecimento nos grupos-pesquisadores. No meu ver, não há contradição entre a estética e a ciência; pelo contrário, a nova ciência integra a estética, assim como ela tem elos fortes com a sabedoria. Tal é nossa ética cognitiva.

\section{Alguns devir-índios?}

Brincamos há mais ou menos um ano de índios, ao realizarmos uma pesquisa em estado de transe ayahuasqueiro ${ }^{4}$, com o tema-gerador: “O que nos ensina a Ayahuasca?". Como estávamos no dia internacional do povo Cigano na primeira sessão, as músicas acompanhando a pesquisa eram músicas ciganas do Oriente, da Espanha, da África, da Rússia, assim como, da deusa indiana Kali (Sarah a Preta, Sará Kali, Santa Sará, padroeira do povo cigano). Utilizamos a técnica do Jogo de Tarô, particularmente apropriado, e criamos o "Tarô da Consciência".

O transe foi muito forte e duradouro nos 11 copesquisadoras/es, que tinham entre 12 meses e 12 anos de prática ritualística regular. Foram utilizadas duas outras técnicas de

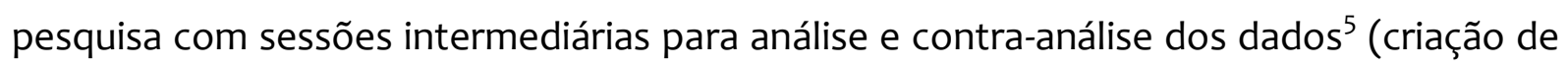
Poemas em Estado de Transe na segunda sessão, e Dança dos Cinco Ritmos, segundo Gabrielle Roth na terceira - sempre em estado de transe, com escrita imediata do Diário de itinerância), sendo finalizada a pesquisa com entrevistas individuais.

Extremamente rica em dados, essa pesquisa ainda não publicada pode criar problemas - como dizia a jovem Judith Butler: estes "problemas", que selecionei entre muitos... Apenas na primeira técnica, no Tarô da Consciência:

\footnotetext{
${ }^{4}$ Sobre as práticas ayahuasqueiras de cura e iluminação, ver o livro de Claudio Naranjo (2015): Ayahuasca - a enredadeira do rio celestial.

5 Para conhecer técnicas e passos do método sociopoético, incluindo o “diário de itinerância”, ver Gauthier (2012).
} 
- A passagem pela dor da explosão-desconstrução é imprescindível. Mas não há dúvida de que as polaridades, identificadas pelo grupo-pesquisador como "sexuais", assim como as polaridades Água-Fogo e Terra-Ar, permitem alcançar o equilíbrio - mesmo que instável - e o discernimento: um espiral traz a superação da dúvida no que diz respeito ao sentido da vida cotidiana. Esse espiral, que tem nome de "fé naquilo que experienciamos" abre um espaço vazio onde são queimadas as ilusões do ego.

- Violência e ternura estão intimamente misturadas no processo pessoal de cura e abertura a uma dimensão espiritual numinosa.

- Criamos os confetos e intuicetos de "intensidade-concentração-profundidadeampliação”, “perda-presença extrema”, “inacabamento-integração”, "nada-infinito-luzsombra”, “caos-explosão-integração”, “dor-prazer do fazer-potência”, “desapegosaborear" e "fé como confiança íntima na luz da sua própria sombra".

Vê-se que esse tipo de pesquisa não eurodescendente mobiliza seres cognitivos que podemos chamar de intuicetos - misturas de conceitos e intuições, pouco frequentes na academia. Numa visão "intercultural crítica”, conforme a definição dada por Catherine Walsh (2009) - ou seja, que abre espaço para o pensamento decolonial - é fácil perceber que a academia tem dificuldade em entender como as colonizadas e colonizados (provavelmente, nos transes e sonhos dos fiéis do candomblé e da umbanda “acontecem" - para falar como Deleuze e Guattari - intuicetos parecidos) constroem seus conhecimentos e, além dos conhecimentos, seus "valores de verdade”... Como diriam Nietzsche ou Foucault (2002).

Sempre estamos frente à mesma pergunta, que elabora magnificamente Sandra Haydée Petit na sua Pretagogia - Pertencimento, corpo-dança afroancestral e tradição oral africana na formação de professoras e professores (PETIT, 2015) e por Maria do Livramento Machado na sua dissertação de Mestrado em Educação orientada pela Profa. Dra. Shara Jane Costa Adad: Jovens bailarinas de Vazantinha: conceitos de corpo nos entrelaces afroancestrais da dança na educação (MACHADO 2015): qual o espaço deixado pelas/os educadoras/es a alunas/os indígenas ou culturalmente afrodescendentes para que possam expressar seus corpos, seus saberes, seus métodos e sua própria espiritualidade - sempre presente nas práticas cognitivas? A educação será realmente crítica - conforme a meta da vida inteira de Paulo Freire - quando interagirão em sala de aula modos de criar 
e cocriar o saber, de experienciar a pulsão de vida, diferenciados e diferenciadores. Todas e todos, negros e brancas, brancos e índias, índios e negras têm a ganhar nessas interações.

\section{Um desafio em forma de conclusão}

Na prática das/os educadoras/es, surge uma certeza: nunca daremos um lugar suficiente ao riso e ao que Judith Butler (2015, p. 215) chama de "deslocamento parodístico e subversivo do poder, ao invés da fantasia impossível de sua completa transcendência" (e, obviamente, da sua imitação/reprodução, que seria nosso suicídio como educadoras/es).

Inventar jogos onde se aprenda, concretamente - para poder entrar depois num movimento coletivo de teorização - como se constitui o artifício das imposições culturais, políticas, raciais, sociais, de gênero etc., a partir de identidades molares binárias (branca/o x negra/o, homem x mulher, burguesa/ês x trabalhador/a etc.) é de capital importância se quisermos uma educação à prática da liberdade e à invenção da cultura, que permita a ocupação de novos espaços com geração de outras relações de poder, saber, gênero etc.

O erê, no candomblé e na umbanda, é forma-criança do orixá. Ele ri de tudo, nada resiste a seu riso desconstruidor, nem o próprio "eu" da/o fiel. Esse riso é compassivo, nunca cruel, mesmo se, como se diz, "a verdade sai da boca das crianças" e nem sempre é agradável a ser ouvida.

Tocamos neste trabalho, provavelmente sem a devida profundidade, um pouco de cada um dos Sete saberes necessários à educação do futuro, conforme Edgar Morin (2011): saberes do erro e da ilusão; conhecimento pertinente; condição humana; identidade terrena; incertezas; compreensão e, por fim, ética do gênero humano.

$\mathrm{Na}$ prática dos novos desafios trazidos pela educação intercultural crítica, aprendemos das/os nossas/os parceiras/os afrodescendentes e indígenas que o gênero humano não pode ser pensado sem que se pense sua inclusão nas ancestralidades da Terra, da Água, do Fogo e do Ar. Traz alegria constatar que essas tradições, durante tanto tempo desprezadas pelas/os colonizadoras/es, estão hoje valorizadas por pensadoras/es europeus ou eurodescendentes, pesquisando na ponta extrema das suas especialidades: Morin e muitas/os outras/os. 
Ao radicalizar minha posição no que diz respeito aos "devires" apontados por Deleuze e Guattari, insisti no livro "O oco do vento" (GAUTHIER, 2012) sobre o devirvacuidade como primeiro devir, chave para as conexões inter e transculturais e portal para todos os outros tipos de devir: devir-criança, devir-mulher, devir-adolescente, devirnegro(a), devir-índio(a) etc. Com efeito, ao esvaziarmos a mente, deixamos entrar o sopro da alteridade e diferença em nós e colocamo-nos em condições de uma verdadeira dialogicidade, interculturalidade crítica e transculturalidade.

É tempo de lembrar a sabedoria do povo indígena Potawatomi, tal como exposta por Robin Wall Kimmener (2013), ao mesmo tempo professora doutora em biologia florestal no Estado de Nova York e iniciada nos saberes botânicos tradicionais do seu povo: três são nossas atitudes básicas em relação às plantas, que sabem sintetizar a Água com o Fogo do sol, o oxigênio do Ar e os nutrimentos da Terra, produzindo nossos alimentos e remédios - o que não sabemos fazer sozinhos. São atitudes de Gratidão, Reciprocidade e Responsabilidade. Essa ética pode ser ampliada a todo ser. 


\section{Referências}

BOAL, Augusto. O Teatro do Oprimido e outras poéticas políticas. $5^{\mathrm{a}}$ ed. Rio de Janeiro: Civilização Brasileira, 1988.

BUTLER, Judith. Problemas de gênero: Feminismo e subversão da identidade. Rio de Janeiro: Civilização Brasileira, 2015.

DELEUZE, Gilles; GUATTARI, Félix. Mille plateaux. Paris: Minuit, 1980.

DELEUZE, Gilles; GUATTARI, Félix. Mil platôs. Vol. 4. São Paulo: Editora 34, 1997.

DETIENNE, Marcel. Dionysos mis à mort. Paris: Gallimard, 1998.

DETIENNE, Marcel. Apollon le couteau à la main. Paris: Gallimard, 2009.

FOUCAULT, Michel. Surveiller et punir: Naissance de la prison. Paris: Gallimard, 1975.

FOUCAULT, Michel. Histoire de la sexualité: 2. L'usage des plaisirs. Paris: Gallimard, 1984.

FOUCAULT, Michel. A arqueologia do saber. São Paulo: Ed. Florense Universitária, 2002.

FREINET, Célestin. A educação do trabalho. São Paulo: Martins Fontes, 1998.

FREIRE, Paulo. Professora sim; tia não: Cartas a quem ousa ensinar. São Paulo: Paz e Terra, 2013.

FREUD, Sigmund. Cinq psychanalyses. Paris: PUF, 2014.

GAUTHIER, Jacques. $\mathrm{O}$ oco do vento: metodologia da pesquisa sociopoética e estudos transculturais. Curitiba: CRV, 2012.

GAUTHIER, Jacques, FLEURI, Reinaldo M., GRANDO, Beleni S. (Orgs). Uma pesquisa sociopoética: o índio, o negro e o branco no imaginário de pesquisadores da área de educação. Florianópolis: UFSC, 2001.

GIACOIA JÚNIOR, Oswaldo. Nietzsche: o humano como memória e como promessa Petrópolis: Vozes, 2013.

GUATTARI, Félix. O capitalismo mundial integrado e a revolução molecular. In. Revolução molecular: pulsações políticas do desejo. São Paulo: Brasiliense, 1981.

GUATTARI, Félix. As três ecologias. Campinas: Papirus, 1990.

GUATTARI, Félix. Caosmose: um novo paradigma estético. Rio de Janeiro, RJ: Edição 34, 1992.

HARDT, Michael; NEGRI, Antonio. Declaração: isto não é um manifesto. São Paulo: n-1 Editora, 2014. 
JUNG, Carl. O Homem e seus símbolos. 13ª . ed. Rio de Janeiro: Nova Fronteira, 1995.

KIMMENER, Robin W. Braiding Sweetgrass: Indigenous Wisdom, Scientific Knowledge, and the Teachings of Plants. Minneapolis: Milkweed, 2013.

LOURAU, René. Análise institucional e práticas de pesquisa. René Lourau na UERJ. Rio de Janeiro: UERJ, depto de Extensão, 1993.

LOURAU, René. A análise institucional. Petrópolis: Vozes, 2014.

MACHADO, Maria do Livramento. Jovens bailarinas de Vazantinha: conceitos de corpo nos entrelaces afroancestrais da dança na educação. 2015. Dissertação (Mestrado em Educação) - UFPI, Teresina, agosto de 2015.

MORIN, Edgar. Os sete saberes necessários à educação do futuro. São Paulo: Cortez, 2011.

NARANJO, Cláudio. Ayahuasca: aenredadeira do rio celestial. Simões Filho: Kalango, 2015.

NIETZSCHE, Friedrich. O nascimento da tragédia. São Paulo: Companhia de Bolso, 2007.

PETIT, Sandra H. Pretagogi: pertencimento, corpo-dança afroancestral e tradição oral africana na formação de professoras e professores. Fortaleza: EdUECE, 2015.

TEDLOCK, Barbara. A mulher no corpo de xamã: o feminismo na religião e na medicina. Rio de Janeiro: Rocco, 2008.

WALSH, Catherine. Interculturalidad, estado, sociedade: luchas (de)coloniales de nuestra época. Quito-Equador: Universidade Andina Simón Bolívar: Ediciones Abya-Yala, 2009. 